\title{
Future of Biotech Equipment/Medical Device Research \& Development: A Case for Redemption of the Neglect
}

\author{
Shyamala Thirunavukkarasu* \\ Department of Molecular Microbiology, Washington University in St Louis, USA \\ *Corresponding author: Shyamala Thirunavukkarasu, Washington University in St Louis, School of Medicine, 660 S. Euclid Avenue, \\ St Louis 63110, USA. \\ To Cite This Article: Shyamala Thirunavukkarasu, Future of Biotech Equipment/Medical Device Research \& Development: A Case for Redemption \\ of the Neglect. Am J Biomed Sci \& Res. 2020 - 7(2). AJBSR.MS.ID.001134. DOI: 10.34297/AJBSR.2020.07.001134.
}

Received: 阱 January 28, 2020; Published: 㘹 February 06, 2020

\section{Introduction}

The global healthcare industry is undergoing a progressive transformation at a rapid pace. Ground breaking innovation across multiple fields including biotechnology, pharmaceutical and medical devices is driving this transformative journey, the main outcome of which is improved patient health and decreased cost burden resulting in enhanced quality of life.

Small molecule drug development and advances in bio therapeutic formulations by various pharmaceutical and biotechnological companies respectively, either alone, or in collaboration with dedicated research groups in academia tend to garner the majority of government and non-governmental funding. However, a critical area of biomedical research that lags behind in comparison with its peers in this category are biomedical devices that are also an integral part of patient therapy. While this disparity is most evident in the developing countries beset with social inequalities and a lack of medical infrastructure [1], even in developed nations leading in biotech innovation such as the US there has been a steady decline in the investment poured into this field with a fall in available funding from 11\% in 2010 to approximately 5\% in 2016 [2]. Collectively, this imbalance could perhaps be applied to the term "10/90 Gap" coined by Global Forum for Health Research [3] to reflect that only 10\% of health research funds are spent on the problem of developing optimum biotech equipment and devices for $90 \%$ of the world's population.

Traditionally, most of the research and development (R\&D) of new and efficient biotech equipment especially smaller medical devices are undertaken by startup companies which invariably depend on funding provided by private equity/venture capitalists. But the risks associated with market stability coupled with slow pace of development including the prolonged process of getting FDA approval oftentimes result in the redirection of finances from these sources towards more lucrative non-medtech sectors wherein the time gap from development to actualization of return is less. The big players, namely the corporate sharks on the other hand are more prone to withhold investing in smaller startups and rather play a wait and watch approach to let the completion of the development and testing process before paying to acquire the business in its entirety.

Despite these setbacks the tides are starting to turn in favor of greater opportunities for those involved in R\&D in the biotech equipment/medical device sector at both the industry and academic levels. The potential for crowd sourcing funds to support startups and establishment of grants to sponsor seed money by Research Institutions is a step in the right direction. It is indeed heartening to note that in the 2018 cycle of the LEAP Inventor Challenge Awards administered by the Skandalaris Center for Interdisciplinary Innovation \& Entrepreneurship at the Washington University in St Louis, 3 out of the 5 awards conferred were in the area of medical device development. As the transformative journey in this previously eclipsed field gathers renewed momentum the hope for further advancements in the future holds promise.

\section{References}

1. D Lustick, M Zaman (2011) Biomedical Engineering Education and Practice Challenges and opportunities in improving health in developing countries.

2. Ben Dunn (2017) Medical Device Funding: Any Signs of Life. In the Medical product Outsourcing Magazine.

3. L Doyal (2002) Poverty and health from a gender perspective. in the 10190 report on health research: 2001-2002 In: S Davey (Ed.), Global Forum for Health Research, Switzerland. 